Journal of Learning and Development Studies (JLDS)

DOI: $10.32996 /$ jlds

Journal Homepage: www.al-kindipublisher.com/index.php/jlds

\title{
A Qualitative Study on Speaking Anxiety among Pre-Service Teachers
}

\author{
Abdu Rahim T. Kenoh III \\ College of Teacher Education, Western Mindanao State University, Philippines \\ Corresponding Author: Abdu Rahim T. Kenoh III, E-mail: abdurahimkenoh@gmail.com
}

\author{
ARTICLE INFO \\ Received: September 12, 2021 \\ Accepted: October 04, 2021 \\ Volume: 1 \\ Issue: 1 \\ DOI: $10.32996 / j l d s .2021 .1 .1 .4$
}

\section{KEYWORDS}

Speaking anxiety, public speaking, pre-service teachers

\section{ABSTRACT}

Despite being competent in the English language, pre-service teachers struggle a lot when it comes to public speaking. Their ability to deliver and speak competently is hindered by speaking anxiety. The purpose of this study is to determine the causes of speaking anxiety among pre-service teachers and identify how pre-service teachers cope up with speaking anxiety. This study was administered to 7 pre-service teachers using a convenience sampling technique from a reputable public state university in Southern Philippines. The findings showed that speaking anxiety among pre-service teachers is caused by the fear of committing mistakes, having high expectations from the audience, nervousness, and lack of preparation. Additionally, the techniques used by pre-service teachers to cope up with speaking anxiety include preparing an outline, practicing before the actual speech, and boosting one's self-confidence. Research revealed that speaking anxiety can be eased by employing techniques such as exposure to speaking engagements, preparation, and believing in oneself.

Published by Al-Kindi Center for Research and Development, London, United Kingdom.

Copyright (c) the author(s). This open access article is distributed under a Creative Commons Attribution (CC-BY) 4.0 license (https://creativecommons.org/licenses/by-nc-nd/4.0/)

\section{Introduction}

Speaking is one of the four macro skills of the English language. It is the process of conveying information verbally. Among the four macro-skills, Egan (1999) stated that speaking is a critical and challenging skill. It requires the ability to process information mentally and produce the language to convey the message verbally. Speaking is also the most important skill required in business and government transactions (Egan 1999). It is the heart of daily conversations, and it is also a mode of communication. In a similar vein, speaking is a skill that is prominent in the teaching profession. Teachers are required to master the skill of public speaking so as not to compromise the teaching-learning process. Thus, requiring would-be teachers to speak confidently and master the said skill.

This being said, a lot of people encounter challenges before and during the act of speaking. One of which is the occurrence of speaking anxiety. According to Zhanibek (2001), speaking anxiety is the fear felt by an individual when speaking. It is the most frequently cited concern of students when asked about the challenges they encounter when speaking. There are several studies conducted as regards the causes of speaking anxiety. Sandin (2017) found out that speaking anxiety is caused by two major factors namely the social aspect and the biological aspect of an individual. Similarly, Ayres \& Hopf (1993) identified the causes of speaking anxiety and classified it into three sub-categories (e.g., Cognitive, Behavioral, and Affective). Raja (2017) asserted that the most common reason for the fear of speaking in public is lack of confidence. There are also studies conducted as regards coping mechanisms on speaking anxiety. Hutabarat \& Simanjuntak (2019) identified media intervention and establishing learning support as the ways to overcome speaking anxiety. Raja (2017) also suggested that strategies such as practicing and rehearsing before the actual performance help alleviate the fear of speaking in public. Similarly, Khusnia (2017) noted that practicing before performing helps in coping up with speaking anxiety.

Having explored these above-mentioned studies, it was observed that if not all, most of the studies were conducted to English as a Foreign Language (EFL) Learners and some are for teachers. However, these studies were not aimed at identifying the causes of speaking anxiety and coping mechanisms of English as a Second Language (ESL) Learners as well as Pre-Service Teachers (PSTs). Exploring ESL learners' and PST's suggestions in terms of the causes of speaking anxiety and their coping mechanisms is significant to providing information that will contribute to the success of the teaching-learning process. 
Therefore, this study is intended to bridge the gap by identifying the causes of speaking anxiety among English as a Second Language Pre-Service Teachers and how they cope up with speaking anxiety. The results of this study will significantly enhance the effectiveness and efficiency of Pre-Service Teachers when teaching in the real world.

\section{Literature Review}

\subsection{Speaking Anxiety}

Speaking Anxiety is the fear felt by an individual when speaking (Zhanibek, 2001). It is the most common problem encountered by speakers whether beginner or novice. As elaborated by Raja (2017), speaking anxiety is the state of uneasiness and apprehension of fear caused by the anticipation of something threatening. It is something felt by the speaker before and/or during speaking. According to the University of Pittsburgh (2021), some of the most common symptoms of speech anxiety are shaking, sweating, butterflies in the stomach, dry mouth, rapid heartbeat, and squeaky voice. These symptoms may not be present all at once, but they indicate that the person showing such symptoms may be experiencing speaking anxiety.

\subsection{Causes of Speaking Anxiety}

As accentuated by Batiha et. al (2016), Speaking Anxiety is primarily caused by the fear of committing mistakes. Speakers tend to be hesitant to speak in public because of the fear of committing mistakes. The University of Pittsburgh (2021) also added that speaking anxiety occurs when the speaker feels that the audience has high expectations. This implies that when the audience is of high educational attainment, has a deeper understanding of the subject matter, and knows the topic very well, the speaker becomes anxious and feels uncomfortable when speaking. This happens mostly to beginner speakers who think and feel that the audience wants them to fail. Another cause of speaking anxiety is the feeling of nervousness. Nervousness, as emphasized by Tsaousides (2017), is very common to "first-time" speakers. It occurs when the speaker lacks experience when speaking in public. Speakers also experience speaking anxiety when there is no preparation done before speaking. As stressed out by Batiha et.al (2017) unpreparedness is the factor that is responsible for speakers' anxiety which hinders the speaker's performance. This means that unprepared speakers experience panic when they are asked to speak in public unprepared. He also added that unprepared speakers generally encounter speaking anxiety more than prepared speakers.

\subsection{Coping Mechanisms of Speaking Anxiety}

Speakers can overcome speaking anxiety with constant practice and persistence (Sawchuk, 2017). There are a lot of ways to deal with speaking anxiety and manage the fear of speaking in public. The University of Hawaii (2002) suggested that preparing before the speech helps reduce anxiety in speaking. This includes the use of backup materials such as note cards and an outline. Additionally, the University of Nevada (2021) asserted that familiarizing the content of the speech helps the natural flow of words and makes the speaker look more confident. It also reduces the chances of committing mistakes. Aside from preparation, practicing one's speech is also important. The University of Hawaii (2002) supported this notion by stating that the more practice you do before speaking, the more confident you become. This means that practicing a lot helps boost self-confidence and eases anxiety when speaking in public. Another technique that can be used to cope up with speaking anxiety is boosting one's self-confidence. This ultimately helps lessen the fear of speaking in public. According to Tridinanti (2018), the relationship between speaking anxiety and self-confidence is inversely proportional. It means that speakers with higher self-confidence, have lower speaking anxiety, making them more confident when speaking in public. This is supported by Van Den Bergh (2021) who emphasized that building confidence is essential in alleviating the fear of speaking in public.

\subsection{Research Questions}

1. What causes speaking anxiety among Pre-Service Teachers?

2. How do Pre-service Teachers cope with speaking anxiety?

\section{Method}

The study employed a descriptive qualitative approach using semi-structured interviews. Yin (2015) emphasized that this type of approach offers researchers an in-depth understanding of a particular phenomenon. It is important to contextualize the data in a Qualitative Study (Harding, 2018). Thus, this study aims to portray the accuracy of the ongoing phenomenon being studied.

\subsection{Participants}

The study was conducted on seven (7) pre-service teachers from a public state university in Southern Philippines. The participants were all studying Bachelor of Secondary Education majoring in English of which four (4) were females and three (3) were males. Participant 1 is a 21-year-old female who is active in public speaking competitions. Participant 2 is also a 21 -year-old female who is a member of the Sangguniang Kabataan of her barangay. Participant 3 is also a 21-year-old female who is an orator. Participant 4 is a 21 -year-old male who is frequently engaged in public speaking through emceeing and hosting. Participant 5 is a 21 -yearold female who won as champion during the regional story-telling contest. Participant 6 is a 22 -year-old male who won as champion in the regional Dagliang Talumpati competition. Participant 7 is also a 22-year-old male who is fond of hosting and 
writing. Convenience sampling was used to identify the participants for this study. The participants were invited by the researcher and their participation is voluntary. The participants were recruited based on two primary criteria, (1) currently in their third year enrolled in the BSED (English) program and (2) has been widely exposed to public speaking through hosting, competitions and programs.

\subsection{Instruments and Data Collection}

A semi-structured interview protocol was developed by the researcher to obtain the required data. The instrument was validated by a Doctor of Philosophy in English Language Teaching and was pilot tested on two pre-service teachers who did not form part of the seven (7) final participants. In assuring compliance to health protocols amidst the COVID-19 Pandemic, the interviews were conducted through phone calls as face-to-face interviews were prohibited as it elevates the risk of contracting the virus. The responses were recorded by the researcher which was allowed by the participants for data analysis purposes only. The semistructured interviews were aligned with the study's research questions and were asked to the participants during the interview. A semi-structured interview is advantageous as it allows new ideas and questions to come up during the interview (Harding, 2018) and it also widens the possible answers of the participants by probing and asking follow-up questions.

\subsection{Method of Analysis}

The data were recorded through phone calls and were analyzed with reference to the procedures of Thematic Analysis. As stated by Caulfield (2019), Thematic Analysis is a technique in analyzing qualitative data that is employed in a set of texts, such as interview transcripts. It provides researchers a rich and detailed account of data (Nowell, Norris, White \& Moules, 2017) This method allows researchers to closely examine obtained data to identify common themes which have patterns of meaning that come up repeatedly. First, the researcher transcribed the responses and encoded it to Microsoft word. Next, the researcher developed themes that are aligned with the participants' responses. Then, the researcher grouped the responses that belong to the same themes. Lastly, the researcher identified the final themes that were developed with respect to the responses.

\section{Findings and Discussion}

This section presents the themes developed from the data that were analyzed with the two research questions about the causes of speaking anxiety and the techniques used by Pre-Service Teachers in coping up with speaking anxiety. The most representative quotes from the responses were presented to support the developed themes.

\subsection{Causes of speaking anxiety among Pre-Service Teachers 4.1.1 Fear of Committing Mistakes}

Based on the data analyzed, the majority of the participants experience speaking anxiety due to the fear of committing mistakes.

"One of the things that make me feel uncomfortable when speaking in public is the fear or the feeling that something might go wrong when I speak" (Participant 7)

The mistakes that the participants are referring to are the errors in speaking and the use of words. Particularly, it zeroes in on the use of the language. A participant said that she fears that she might commit mistakes with the language that she is using.

"I'm afraid I'm gonna make mistakes especially with the language that I use" (Participant 2)

This fear also includes the grammatical aspect of language. The correct use of the rules of grammar highly affects the fear of speaking in public.

"Aside from getting intimidated I am afraid that I might not be speaking the right way or there may be grammatical errors" (Participant 3)

The fear of committing mistakes is deemed to be one of the primary causes of speaking anxiety (Batiha, Mustafa, Mohd Noor, 2016). This means that the primary reason why learners fear speaking in public is that they fear that they might commit errors while speaking which is related to the fear of the audience having high expectations.

\subsubsection{Fear of having High Expectations from the Audience}

Another cause of speaking anxiety is fear of having high expectations from the audience. One of the participants emphasized that the fear of speaking in public is entailed to the audience having high expectations. This includes the things that are meant to be heard by the audience.

"Sometimes, I am in fear of not meeting the audience's expectations especially the jury" (Participant 6) 
Though this does not happen all the time, one participant asserted that the fear of high audience expectations is also related to the fear of the audience not agreeing with what he is saying.

"I'm afraid of too many people watching me and they will not appreciate [agree with] the ideas that I would be sharing with them" (Participant 4)

Additionally, this particular fear also creates pressure at the end of the speaker which is primarily aimed at getting the audience's expectation to match the speaker's performance.

"Instead of focusing on my lines I tend to think of they should go along with me and they should vibe [agree] with what I am saying" (Participant 5)

According to the University of Pittsburgh (2021), the fear of the audience having high expectations is commonly felt by novice speakers. This happens when speakers view their audience as critical and want them to fail. This implies that speakers who are easily intimidated by the audience tend to fear the high expectations of the audience. This fear is connected to making the speakers feel nervous before and during speaking.

\subsubsection{Nervousness}

Another cause of speaking anxiety is the feeling of nervousness. This particular cause is generated by the aforementioned causes as stated by one of the participants.

"I was very nervous that time because maybe they didn't like the way I performed" (Participant 5)

Nervousness also affects the actual performance of the speaker. It causes pressure and results in changes in the speaker's performance such as bodily movements, gestures, and voice.

"That time I was very nervous, and I sound similarly like a broken record" (Participant 4)

According to Tsaousides (2017), the feeling of nervousness when speaking is due to the lack of experience of the speaker. Most "first-time" speakers are nervous when it comes to speaking in public because they have not yet experienced the actual speaking engagement. This can also be generated when the speaker is unprepared.

\subsubsection{Lack of Preparation}

Probably the most general cause of speaking anxiety is the lack of preparation. This includes the speaker's preparations as regards the content of the speech, the speaker's appearance as well as the conditioning of the self and the mind.

"I'm also afraid to speak when I am not prepared with what I am about to say when I am asked to speak in front. I also do not like to speak when I am not dressed well and when me myself is not in the mood" (Participant 1)

Unprepared speakers generally encounter speaking anxiety more than prepared speakers. As stressed out by Batiha et.al (2017) unpreparedness is the factor that is responsible for speakers' anxiety which hinders the speaker's performance. This means that unprepared speakers panic when they are asked to speak unprepared which makes preparation vital in battling speaking anxiety.

\subsection{Techniques used by Pre-Service Teachers in coping up with Speaking Anxiety} 4.2.1 Preparing an Outline

Preparation is the most common practice the participants do before performing. This includes doing an outline before the actual delivery of the speech.

\section{7)}

"[Before speaking in public], most of the time I prepare. I do an outline of the things that I need to say." (Participant

Additionally, it also entails preparing oneself and familiarizing oneself with the things that are to be said while speaking.

"I usually prepare myself before speaking like I prepare an outline and familiarize myself with what I am going to say so that I would not go out of track" (Participant 2)

Preparation also includes outlining the parts of the speech to ensure that the speech will be performed well. 
"I always prepare an intro and a little outro for me to start and end the speech well" (Participant 1)

The University of Hawaii (2002) pointed out that one way to reduce speaking anxiety is to make sure that you are well prepared, and you have some backup materials such as note cards and an outline. This means that speakers who prepare an outline generally feel less anxious when speaking because of the belief that they have prepared themselves before the speech. Additionally, The University of Nevada (2021) asserted that knowing the introduction helps words to flow naturally and it makes the speaker more confident in beginning and ending the speech. Preparation also reduces the chances of committing mistakes.

\subsubsection{Practicing before the speech}

In connection with preparing an outline, practicing before the actual speech helps ease the participants' fear of speaking in public. This helps ensure that there is mastery of the performance.

"I have tried performing in front of the mirror, to help me practice the emotions that I need to portray and help me master the way how my speech should go" (Participant 5)

Similarly, practicing with a coach or a trainer helps lessen the anxiety when speaking as it allows feedback, and it ensures a seamless delivery of the speech as well as develops the speaker's speaking skills.

"I always make sure that I am constantly practicing with my trainer, coaches, and critiques and I always see to it that I see it [criticisms] objective(ly) for me to develop my speaking skills, delivery skills, and the like. (Participant 6)

Aside from preparing an outline, practicing one's speech is extremely important. The more practice you do before speaking, the more confident you become (University of Hawaii, 2002). This implies that practicing a lot helps boost self-confidence and eases anxiety when speaking in public. Sandin (2017) claims that in order for students to handle speaking anxiety, they must constantly practice speaking. This means that speaking anxiety can be managed when speakers practice their speech before the actual speaking. Corroborating this claim, Isnaini (2019) noted that practicing helps increase speaking skills. It develops the speaker's skill in delivering the speech as well as boosts the speaker's self-confidence.

\subsubsection{Boosting Self-Confidence}

Added to the list of the techniques pre-service teachers use to cope up with speaking anxiety is boosting one's self-confidence as it helps lessen the participants' fear of speaking in public. One way to do so is to think that you are in control of the crowd.

"One of the things I do is to think that I am the one who is leading the crowd because I am the one who is speaking, and it that way, I feel confident, and I feel like I can really speak out what I want to say" (Participant 1)

It also enables the participants to eliminate negativity and continue doing their best in speaking.

"There are times that I tell myself 'if other people can do it, why not yourself?' and I also try to tell myself that I need to believe in myself sometimes even though you're not that good at speaking" (Participant 3)

Believing in oneself also boosts the participants' self-confidence when speaking in public. It entails being calm and bearing in mind not to panic.

The coping mechanism that I practice is that I always bear in mind that I have to be calm, I should not panic and I have to believe that I can do that [speaking]" (Participant 4)

According to Tridinanti (2018), there is an inversely proportional relationship between speaking anxiety and self-confidence. The higher self-confidence, the lower the speaking anxiety. This implies that speakers who build confidence before speaking tend to experience less fear when speaking in public. Supportive of this claim is Van Den Bergh (2021) who emphasized that building confidence is essential in alleviating the fear of speaking in public.

\section{Conclusion}

This study highlights the causes of speaking anxiety among Pre-Service Teachers as well as the techniques used by Pre-Service Teachers in coping up with speaking anxiety. The findings reveal that speaking anxiety among Pre-Service Teachers is primarily caused by four factors. (1) Fear of committing mistakes, (2) Fear of high expectations from the audience, (3) Nervousness, and (4) Lack of preparation. The fear of committing mistakes generally refers to the errors done while speaking. It also includes the misuse 
of the language and grammatical errors. The participants also get anxious when they feel that the audience is expecting a lot from them, be it their performance, their appearance, or the content of their speech. Nervousness also comes in especially when the participants lack experience in public speaking. This also relates to the lack of preparation. When the participants feel that they are unprepared, it makes them feel scared or anxious about what might go wrong with their performance. As regards how Pre-Service Teachers cope up with Speaking Anxiety, the findings reveal three particular techniques. (1) Preparing an outline, (2) Practicing before the speech, and (3) Boosting self-confidence. Preparing an outline helps the participants to be more familiar with the content of their speech, making their delivery seamless. The participants also stressed out that boosting one's self-confidence helps lower the fear of speaking in public. Steps like taking control over the crowd, believing in oneself, and staying calm while speaking help the participants in building their self-confidence.

\subsection{Implications}

The findings of this study will help higher education institutions to identify the causes of Speaking Anxiety among Pre-Service Teachers and provide training programs that would help Pre-Service Teachers cope up with Speaking Anxiety. It would also develop the public speaking skills of Pre-Service Teachers and prepare them to engage in the real world of teaching.

\section{References}

[1] Ayres, J., \& Hopf, T. (1993). Coping with Speech Anxiety. Norwood, New Jersey: Ablex.

[2] Batiha, J., Mustafa, R. \& Mohd Noor, N. (2016). Speaking anxiety among English as a foreign language learners in Jordan: Quantitative research. International Journal of Education and Research, 4(10), 63-82.

[3] Caulfield, J. (2019, September 6). How to do Thematic Analysis? Retrieved from Scribbr: https://www.scribbr.com/methodology/thematicanalysis/

[4] Egan, K. (1999). Speaking: A Critical Skill and a Challenge. CALICO Journal, 16(3), 277-293.

[5] Harding, J. (2018). Qualitative data analysis: From start to finish. SAGE Publications Limited.

[6] Hutabarat, A. \& Simanjuntak, D. (2019). A phenomenological study: speaking anxiety overwhelms English learners. Acuity: Journal of English Language Pedagogy, Literature, and Culture, 4(1), 44-58.

[7] Insaini, N. (2019, February 13). Repository. Retrieved from Raden Intan State Islamic University: http://repository.radenintan.ac.id/5800/

[8] Khusnia, A. (2017). Students' speaking anxiety in English foreign language. Journal of Education and Learning, 11(1), 83-90.

[9] Nowell, L., Norris, J., White, D. \& Moules, N. (2017). Thematic analysis: Striving to meet the trustworthiness criteria. International Journal of Qualitative Methods, 1(16).

[10] Raja, H. (2017). The anxiety level in students of public speaking: Causes and remedies. Journal of Education and Educational Development, 4(1), 94-110.

[11] Sandin, D. (2017). Talrädsla i skolan: att förstå och hjälpa elever som inte gillar att. Stockholm: Gothia fortbildning.

[12] Speech Anxiety: Tame the Extra Energy. (2002, January 16). Retrieved from University of Hawaii: https://www.hawaii.edu/mauispeech/html/speechanxiety.html\#: :text=The\%20way\%20to\%20reduce\%20the,speech\%20on\%20speech\%20d ay)\%20as

[13] Tridinanti, G. (2018). The correlation between speaking anxiety, self-confidence, and speaking achievement of undergraduate EFL students of a private university in Palembang. International Journal of Education \& Literacy Studies, 4(6), 35-39.

[14] Tsaousides, T. (2017, November 17). Why Are We Scared of Public Speaking? Retrieved from Psychology Today: https://www.psychologytoday.com/us/blog/smashing-the-brainblocks/201711/why-are-we-scared-publicspeaking\#: :text=The\%20fear\%20often\%20arises\%20when,chance\%20to\%20reach\%20an\%20audience.

[15] The University of Nevada. (2021, May 27). Speech Anxiety. Retrieved from the University of Nevada, Reno: https://www.unr.edu/writingspeaking-center/student-resources/writing-speaking-resources/speech-anxiety

[16] The University of Pittsburgh. (2021, May 26). Speech Anxiety. Retrieved from University of Pittsburgh: comm.pitt.edu/speech-anxiety

[17] Van Den Bergh, E. (2021, May 27). Nine tips to immediately speak with more confidence and impact. Retrieved from Montis Public Speaking: https://www.speaker.coach/wp-content/uploads/2018/01/eBook-MONTIS_9_tips.pdf

[18] Yin, R. K. (2015). Qualitative research from start to finish. Guilford publications.

[19] Zhanibek, A. (2001). The relationship between language anxiety and students' participation in foreign language classes. (Unpublished Mater's Thesis), Bilkent University, Ankara, Turkey 